Slavica

bruxellensia

\section{Slavica bruxellensia}

Revue polyphonique de littérature, culture et histoire

slaves

$3 \mid 2009$

Pensée des hommes

\title{
Sophie Ollivier, Paoustovski, l'homme du dégel
}

\section{Nicolas Litvine}

\section{OpenEdition \\ Journals}

Édition électronique

URL : http://journals.openedition.org/slavica/711

DOI : 10.4000/slavica. 711

ISSN : 2034-6395

Éditeur

Université libre de Bruxelles - ULB

\section{Édition imprimée}

Pagination : 105-106

ISSN : 2031-7654

\section{Référence électronique}

Nicolas Litvine, « Sophie Ollivier, Paoustovski, l'homme du dégel », Slavica bruxellensia [En ligne], 3 | 2009, mis en ligne le 15 juin 2009, consulté le 22 septembre 2020. URL : http://journals.openedition.org/ slavica/711 ; DOI : https://doi.org/10.4000/slavica.711

Ce document a été généré automatiquement le 22 septembre 2020.

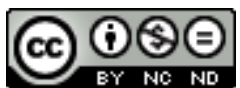

Les contenus de Slavica bruxellensia sont mis à disposition selon les termes de la Licence Creative Commons Attribution - Pas d'Utilisation Commerciale - Pas de Modification 3.0 France. 


\section{Sophie Ollivier, Paoustovski, l'homme du dégel}

Nicolas Litvine

\section{RÉFÉRENCE}

Sophie Ollivier, Paoustovski, l'homme du dégel, L'Harmattan, Paris, 2008, 280 p. 
1 L'écrivain russe Konstantin Georgievič Paustovskij, né en 1892 et mort en 1968, est aujourd'hui, après avoir vu un certain nombre de ses œuvres publiées en français dans les années 1960 et 1970, largement méconnu.

2 En mettant à l'honneur cet artiste dans une monographie de quelques 280 pages (comprenant, outre le texte, un certain nombre de photographies illustrant la vie et la carrière de l'écrivain), Sophie Ollivier entend donc combler un vide regrettable dans l'étude de la littérature russe moderne. Au fil des pages, elle passe en revue la vie et surtout l'œuvre de Paustovskij selon un plan alliant le chronologique et le thématique. La tentative en soi mérite l'intérêt en ce qu'elle rappelle l'œuvre d'un écrivain retombé dans l'oubli. Par contre, on

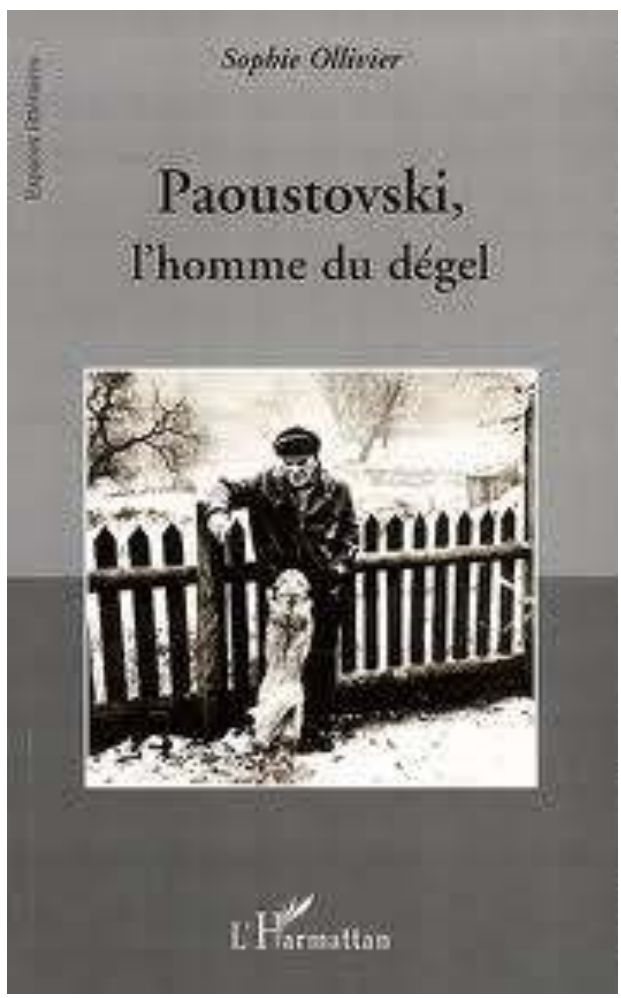
regrettera un ton qui, tout en n'étant pas totalement dépourvu de sens critique, tend sans doute quelque peu à l'hagiographie. Ainsi, tout en étant convaincante lorsqu'elle évoque la rébellion et le courage de l'écrivain défendant à plusieurs reprises ses pairs injustement attaqués, l'auteure l'est moins dans d'autres passages où il semble que toute originalité dans l'œuvre de Paustovskij doit être interprétée comme une révolte, comme s'il était nécessaire que l'écrivain soit un opposant, un dissident avant la lettre pour mériter l'attention.

De manière plus générale, le livre dégage l'impression d'un choix qui n'a pas pu ou pas voulu être fait entre une biographie littéraire et un livre strictement scientifique, tentant d'effectuer une narration et d'exprimer des émotions relevant de la première, sans s'affranchir du style plus neutre du second, et si la passion de l'auteure pour son sujet transparaît clairement dans le texte, la multitude des détails biographiques et intertextuels peut faire perdre le fil des idées.

4 Cela dit, l'ouvrage garde la grande qualité d'être, à notre connaissance, la première étude francophone de cette ampleur consacrée à Paustovskij, et de remettre à l'honneur un de ces écrivains de l'époque soviétique qu'on a sans doute trop facilement tendance à enfermer dans une « parenthèse de l'histoire »... 
INDEX

Index géographique : Russie

Index chronologique : communisme

Mots-clés : dégel, glasnost

\section{AUTEURS}

\section{NICOLAS LITVINE}

Étudiant à l'Université Libre de Bruxelles en Langues et Littératures modernes, orientation slaves 